\title{
Seroprevalence of Toxoplasma gondii Infection among HIV/AIDS Patients in Eastern China
}

\author{
Guoqiang Shen*, Xiaoming Wang, Hui Sun, Yaying Gao \\ Department of Laboratory Medicine, Wuxi No. 9 People's Hospital, 999 Liangxi Road, Wuxi City, Jiangsu Province 214062, China
}

\begin{abstract}
Toxoplasmosis, a neglected tropical disease caused by the protozoan parasite Toxoplasma gondii, occurs throughout the world. Human T. gondii infection is asymptomatic in $80 \%$ of the population; however, the infection is lifethreatening and causes substantial neurologic damage in immunocompromised patients such as HIV-infected persons. The major purpose of this study was to investigate the seroprevalence of $T$. gondii infection in subjects infected with HIV/ AIDS in eastern China. Our findings showed $9.7 \%$ prevalence of anti-T. gondii lgG antibody in HIV/AIDS patients, which was higher than in intravenous drug users $(2.2 \%)$ and healthy controls (4.7\%), while no significant difference was observed in the seroprevalence of anti-Toxoplasma lgM antibody among all participants $(P>0.05)$. Among all HIV/AIDS patients, 15 men (7.7\%) and 10 women (15.9\%) were positive for anti-T. gondii IgG antibody; however, no significant difference was detected in the seroprevalence of anti-Toxoplasma lgG antibody between males and females. The frequency of anti-Toxoplasma lgG antibody was 8.0\%, 13.2\%, 5.5\%, and $0 \%$ in patients with normal immune function (CD4 ${ }^{+}$T-lymphocyte count $\geq 500 \mathrm{cells} / \mathrm{ml}$ ), immunocompromised patients (cell count $\geq 200$ and $<500 \mathrm{cells} / \mathrm{ml}$ ), severely immunocompromised patients (cell count $\geq 50$ and $<200 \mathrm{cells} / \mathrm{ml}$ ), and advanced AIDS patients, respectively (cell count $<50$ cells $/ \mathrm{ml}$ ), while only 3 immunocompromised patients were positive for anti-T. gondii lgM antibody. The results indicate a high seroprevalence of T. gondii infection in HIV/AIDS patients in eastern China, and a preventive therapy for toxoplasmosis may be given to HIV/AIDS patients based on CD4+ $\mathrm{T}$ lymphocyte count.
\end{abstract}

Key words: Toxoplasma gondii, HIV/AIDS, seroprevalence, eastern China

Toxoplasmosis is a worldwide neglected tropical disease caused by the intracellular protozoan named Toxoplasma gondii [1]. Humans usually become infected through the ingestion of undercooked meat containing the encysted stage of the parasite (tissue cysts) or food and water contaminated with cat faces containing oocysts [2]. Transmission also occurs due to the congenital infection through the placenta [3]. In addition, people may get infected by blood transfusion or organ transplantation [4].

T. gondii infections occur throughout the world [1]. Epidemiological evidence shows that one third of the world population has been in contact with the parasite; however, the infection rate varies greatly by country. The foci of high prevalence are detected in Latin America (about 50-80\%), parts of Eastern/Central Europe (about 20-60\%), the Middle East (about 30-50\%), parts of Southeast Asia (about 20-60\%), and Africa

\footnotetext{
- Received 15 October 2015, revised 16 November 2015, accepted 26 November 2015. *Corresponding author (smartsci2013@163.com) (c) 2016, Korean Society for Parasitology and Tropical Medicine This is an Open Access article distributed under the terms of the Creative Commons Attribution Non-Commercial License (http://creativecommons.org/licenses/by-nc/3.0) which permits unrestricted non-commercial use, distribution, and reproduction in any medium, provided the original work is properly cited.
}

(about 20-55\%), while a trend towards lower seroprevalence is observed in many European countries and USA (10.2$11.8 \%$ ) [5]. An estimated $80 \%$ of the subjects infected with the parasite is asymptomatic, as tissue cysts can persist indefinitely during the host's life [6]; however, the infection is life-threatening and causes substantial neurologic damage if an individual becomes immunocompromised, such as HIV/AIDS patients, and organ transplantation recipients [7]. In pregnant women, T. gondii infection may lead to devastating disease for the fetus and newborn infant, later impact on the child's health and development and potentially on his/her later productivity [8]. In the current study, we investigated the seroprevalence of T. gondii infection in subjects infected with HIV/AIDS in eastern China, and compared it with that detected in drug users and healthy population.

The blood samples of 259 HIV/AIDS patients were collected from Wuxi, Jiangsu province, eastern China, and all diagnoses were confirmed by Western blotting assay. Total 90 serum samples were collected from drug addicts in Wuxi Municipal Compulsory Drug Rehabilitation Center (Wuxi, China), and all these subjects had a history of intravenous drug use, while the sera collected from 85 healthy individuals that were pro- 
vided by the Wuxi Municipal Center for Disease Control and Prevention, China (Wuxi, China) served as controls. This study was approved the Institutional Review Committee of Wuxi No. 9 People's Hospital (XJY2011-0128). Signed informed consent was obtained from all participants, following the detailed description of the potential purpose of this study.

Serum samples were assayed for anti-Toxoplasma IgG and IgM antibodies using an ELISA kit (Zhuhai Haitai Biological Pharmaceuticals Co., Zhuhai, China) following the manufacturer's instructions. Absorbance was measured at $450 \mathrm{~nm}\left(A_{450}\right)$ with a Bio-Cell ${ }^{\mathrm{TM}}$ microtiter plate reader (BioTek; Winooski, Vermont, USA). The cut-off value was 2.5 times than the mean absorbance value for controls. Positives were considered as such when $A_{450}$ values were higher than the cut-off.

The $\mathrm{CD} 4^{+} \mathrm{T}$-lymphocyte count in the blood samples from HIV/AIDS patients was determined using a FACSCalibur ${ }^{\mathrm{ru}}$ flow cytometer (BD; San Jose, California, USA). All patients were grouped according to the $\mathrm{CD} 4^{+}$T-lymphocyte count. $\mathrm{CD} 4^{+} \mathrm{T}$ lymphocyte count of $\geq 500$ cells/ml was defined as normal immune function; a count of $<500$ cells/ml and $\geq 200$ cells/ $\mathrm{ml}$ was considered immunocompromised; a count of 200 cells $/ \mathrm{m}$ and $\geq 50$ cells $/ \mathrm{ml}$ was considered severely immunocompromised, while a count of $<50$ cells/ml was defined as advanced AIDS [9]. The seroprevalence of T. gondii infection was detected and compared among various groups of HIV/ AIDS patients.

All data were double-entered into Microsoft Excel 2007 (Microsoft Corporation; Redmond, Washington, USA) and all statistical analyses were performed using the statistical software SPSS version 17.0 (SPSS Inc., Chicago, Illinois, USA). Differences of proportions were tested for statistical significance with the chi-square test. A $P$-value $<0.05$ was considered statistically significant.

Our findings showed the highest seroprevalence of antiToxoplasma IgG antibody in the HIV/AIDS patients, while the lowest seroprevalence was found in intravenous drug users. The frequency of anti-Toxoplasma IgG antibody was significantly greater in HIV/AIDS patients than in intravenous drug users $\left(\chi^{2}=4.18, P<0.05\right)$, with no other significant differences observed. There was no significant difference in the seroprevalence of anti-Toxoplasma IgM antibody among all participants (Table 1).

Of the 259 HIV/AIDS patients, 50 cases (19.3\%) had normal immune function, 129 cases (49.8\%) were immunocompromised, 73 cases $(28.2 \%)$ were severely immunocompromised, and 7 cases (2.7\%) had advanced AIDS. A total of 201 cases (80.7\%) had immune dysfunctions. Among all HIV/ AIDS patients, 15 men (7.7\%) and 10 women (15.9\%) were

Table 1. Frequency of anti-Toxoplamsa lgG and lgM antibodies

\begin{tabular}{|c|c|c|c|c|}
\hline \multirow{2}{*}{ Subjects } & \multicolumn{2}{|c|}{ Anti-Toxoplasma lgG antibodya } & \multicolumn{2}{|c|}{ Anti-Toxoplasma IgM antibody } \\
\hline & No. cases & Seroprevalence (\%) & No. cases & Seroprevalence (\%) \\
\hline HIV/AIDS patients & 259 & 9.7 & 259 & 1.2 \\
\hline Intravenous drug users & 90 & 2.2 & 90 & 0 \\
\hline Healthy controls & 85 & 4.7 & 85 & 1.2 \\
\hline
\end{tabular}

${ }^{a}$ The prevalence of anti-Toxoplasma lgG antibody was significantly greater in HIV/AIDS patients than that in intravenous drug users $(P<0.05)$, with no other significant differences observed $(P>0.05)$.

${ }^{\mathrm{b}}$ There was no significant difference in the prevalence of anti-Toxoplasma IgM antibody among the three types of study subjects $(P>0.05)$.

Table 2. Frequency of anti-Toxoplamsa IgG antibody in HIV/AIDS patients with different CD4+ T-lymphocyte counts

\begin{tabular}{|c|c|c|c|c|c|c|}
\hline \multirow{2}{*}{ Immune function } & \multicolumn{2}{|r|}{ Men } & \multicolumn{2}{|c|}{ Women } & \multicolumn{2}{|r|}{ Total } \\
\hline & No. cases & Seroprevalence (\%) & No. cases & Seroprevalence (\%) & No. cases & Seroprevalence (\%) \\
\hline Normal $^{a}$ & 40 & 10 & 10 & 0 & 50 & 8 \\
\hline Immunocompromised ${ }^{\mathrm{b}}$ & 97 & 9.3 & 32 & 25 & 129 & 13.2 \\
\hline Severely immunocompromised ${ }^{c}$ & 53 & 3.8 & 20 & 10 & 73 & 5.5 \\
\hline Advanced AIDS ${ }^{d}$ & 6 & 0 & 1 & 0 & 7 & 0 \\
\hline
\end{tabular}

ap $>0.05$, men vs women.

${ }^{\mathrm{b}} \mathrm{P}<0.05$, men vs women.

${ }^{c} P>0.05$, men vs women.

${ }^{\mathrm{d}} P>0.05$, men vs women. 
positive for anti-T. gondii IgG antibody; however, no significant difference was detected in the seroprevalence of anti-Toxoplasma IgG antibody between males and females. The frequency of anti-Toxoplasma IgG antibody was $8 \%, 13.2 \%, 5.5 \%$, and $0 \%$ in patients with normal immune functions, immunocompromised patients, severely immunocompromised patients, and advanced AIDS patients, respectively (Table 2). There were only 3 immunocompromised patients positive to anti-T. gondii IgM antibody. A higher prevalence of anti-Toxoplasma IgG antibody was detected in women with HIV/AIDS (15.9\%) than in men (7.7\%); however, no significant difference was observed $(P>0.05)$. In immunocompromised subjects, the prevalence of anti-Toxoplasma IgG antibody was significantly greater in women $(25 \%)$ than in men $(9.3 \%)\left(\chi^{2}=5.2, P<0.05\right)$, while no other gender differences were found (Table 2 ).

Although T. gondii infection has a high prevalence, it does not cause apparent syndromes or only induces mild self-limited diseases in subjects with normal immune functions [6]. The long-term latent infection, however, may be activated and lead to pathological changes after the host's immune function is impaired [10]. In immunocompromised subjects, the infection may expand all through the body and cause severe visceral toxoplasmosis [11]. Toxoplasmosis is therefore considered as a consequence of recurrence of a previously latent infection in most AIDS patients, and the prevalence was estimated to be 20-47\% in HIV-seropositive subjects without preventive interventions [12].

A high seroprevalence of anti-T. gondii $\operatorname{IgG}$ antibody has been reported in HIV-infected subjects [13-15]. To our knowledge, however, there is little information on the prevalence of T. gondii infection in HIV/AIDS patients in eastern China. In the current study, the seroprevalence of anti-Toxoplasma IgG antibody was $9.7 \%$ in HIV/AIDS patients, which was higher than in intravenous drug users and healthy persons. Our findings demonstrate a high seroprevalence of $T$. gondii infection in HIV/AIDS patients, suggesting that HIV-infected populations should be protected from $T$. gondii infection to reduce the prevalence and morbidity and burden of the disease.

The detection of anti-Toxoplasma IgM antibody demonstrates the presence of a recent infection for the first time [16]. In this study, anti-T. gondii IgM antibody was detected in only 3 (1.2\%) immunocompromised patients, who still had some immune functions; however, $80.7 \%$ of the HIV/AIDS patients developed immune function impairments at various degrees, inferring the possibility of recurrence of previously latent $T$. gondii infection in most patients. Our findings demonstrated a high prevalence of T. gondii infection and the development of immune function impairments at various levels in HIV/AIDS patients in China. It is therefore suggested that the parasite $T$. gondii, as a major opportunistic pathogen, be involved in the detection and monitoring of HIV/AIDS based on detection of IgG antibodies.

The subgroup analysis of $\mathrm{CD} 4^{+}$T-lymphocyte counts revealed the highest prevalence of anti-T. gondii IgG antibodies in immunocompromised patients (CD4 ${ }^{+}$T-lymphocyte count $<500$ cells $/ \mathrm{ml}$ and $\geq 200$ cells/ml), followed by patients with normal immune functions (cell count $\geq 500$ cells $/ \mathrm{ml}$ ), while no seropositives were detected in advanced AIDS patients (cell count $<50$ cells/ml). In addition, the present study showed a higher seroprevalence of anti-T. gondii IgG antibody in women than men. Such a finding may be associated with activation of the cyst or pseudocyst, which is easily induced by the high estrogen level [17].

Currently, the 3 major routes for HIV transmission (sexual contact, exposure to infected body fluids or tissues, and vertical transmission) are all present in China [18]; however, intravenous drug users will be the population at highest risk of the infection [19]. In the current study. the prevalence of anti-T. gondii IgG antibody was $2.2 \%$ in drug users, which was significantly lower than that in HIV/AIDS patients (7.7\%) and even lower than in healthy controls (4.7\%), indicating that transmission through blood is not a major route for T. gondii transmission. In addition, the drug users still have comparative normal immune systems, and drug uses cause the alteration of the lifestyle, which leads to a low opportunity to have opportunistic infections.

In conclusion, the results of this study demonstrate a high seroprevalence of T. gondii infection in HIV/AIDS patients, and the risk of relapse of a previously latent infection increases with the reduction in the host's immune function, notably in immunocompromised subjects. The surveillance of T. gondii infection is suggested in HIV/AIDS patients for the early diagnosis of the disease, and preventive therapy may be given to those positive for anti-T. gondii specific IgG antibody, based on the $\mathrm{CD} 4{ }^{+} \mathrm{T}$-lymphocyte counts, to slow the progression of the disease. Since the immune functions of the HIV/AIDS patients are progressively impaired, the detection of specific anti-T. gondii IgG antibody may not coincide with the real status of $T$. gondii infection at the middle and late stages of HIV infection. The addition of PCR assay to routine antibody-based immu- 
nological diagnosis may more accurately reflect the real $T$. gondii infection in HIV/AIDS patients [20].

\section{ACKNOWLEDGMENTS}

We would like to thank all participants involved in this study. Thanks are also addressed to Wuxi Municipal Center for Disease Control and Prevention, China for their kind provision of human sera.

\section{CONFLICT OF INTEREST}

The authors declare no conflicts of interest related to this study.

\section{REFERENCES}

1. Furtado JM, Smith JR, Belfort R Jr, Gattey D, Winthrop KL. Toxoplasmosis: a global threat. J Glob Infect Dis 2011; 3: 281-284.

2. Jones JL, Dubey JP. Foodborne toxoplasmosis. Clin Infect Dis 2012; 55: 845-851.

3. Montoya JG, Liesenfeld O. Toxoplasmosis. Lancet 2004; 363: 1965-1976.

4. Singh G, Sehgal R. Transfusion-transmitted parasitic infections. Asian J Transfus Sci 2010; 4: 73-77.

5. Pappas G, Roussos N, Falagas ME. Toxoplasmosis snapshots: global status of Toxoplasma gondii seroprevalence and implications for pregnancy and congenital toxoplasmosis. Int J Parasitol 2009; 39: 1385-1394.

6. Hill D, Dubey JP. Toxoplasma gondii: transmission, diagnosis and prevention. Clin Microbiol Infect 2002; 8: 634-40.

7. Halonen SK, Weiss LM. Toxoplasmosis. Handb Clin Neurol 2013; 114: 125-145.

8. Montoya JG, Remington JS. Management of Toxoplasma gondii infection during pregnancy. Clin Infect Dis 2008; 47: 554-566.

9. Simon V, Ho DD, Abdool Karim Q. HIV/AIDS epidemiology, pathogenesis, prevention, and treatment. Lancet 2006; 368: 489504.

10. Ambroise-Thomas P. Parasitic diseases and immunodeficiencies. Parasitology 2001; 122: S65-S71.

11. Galvan-Ramirez Mde L, Troyo R, Roman S, Calvillo-Sanchez C, Bernal-Redondo R. A systematic review and meta-analysis of Toxoplasma gondii infection among the Mexican population. Parasit Vectors 2012; 5: 271.

12. Flegr J, Prandota J, SovičkováM, Israili ZH. Toxoplasmosis--a global threat. Correlation of latent toxoplasmosis with specific disease burden in a set of 88 countries. PLoS One 2014; 9: e90203.

13. Minbaeva G, Schweiger A, Bodosheva A, Kuttubaev O, Hehl AB, Tanner I, Ziadinov I, Torgerson PR, Deplazes P. Toxoplasma gondii infection in Kyrgyzstan: seroprevalence, risk factor analysis, and estimate of congenital and AIDS-related toxoplasmosis. PLoS Negl Trop Dis 2013; 7: e2043.

14. Walle F, Kebede N, Tsegaye A, Kassa T. Seroprevalence and risk factors for Toxoplasmosis in HIV infected and non-infected individuals in Bahir Dar, Northwest Ethiopia. Parasit Vectors 2013; 6: 15.

15. Domingos A, Ito LS, Coelho E, Lúcio JM, Matida LH, Ramos AN Jr. Seroprevalence of Toxoplasma gondii IgG antibody in HIV/ AIDS-infected individuals in Maputo, Mozambique. Rev Saude Publica 2013; 47: 890-896.

16. Moncada PA, Montoya JG. Toxoplasmosis in the fetus and newborn: an update on prevalence, diagnosis and treatment. Expert Rev Anti Infect Ther 2012; 10: 815-828.

17. Xiao Y, Yin J, Jiang N, Xiang M, Hao L, Lu H, Sang H, Liu X, Xu H, Ankarklev J, Lindh J, Chen Q. Seroepidemiology of human Toxoplasma gondii infection in China. BMC Infect Dis 2010; 10: 4.

18. Zhang KL, Detels R, Liao S, Cohen M, Yu DB. China's HIV/AIDS epidemic: continuing challenges. Lancet 2008; 372: 1791-1793.

19. Vermund SH. HIV/AIDS trends in China. Lancet Infect Dis 2013; 13: 912-914.

20. Switaj K, Master A, Skrzypczak M, Zaborowski P. Recent trends in molecular diagnostics for Toxoplasma gondii infections. Clin Microbiol Infect 2005; 11: 170-176. 